\title{
Sensoriamento remoto multifonte aplicado na detecção do fitoplâncton em águas interiores
}

\author{
Rejane E. Cicerelli ${ }^{1} \&$ Maria de L. B. T. Galo ${ }^{2}$
}

Palavras-chave:
sensoriamento remoto da água
cianobactérias
clorofila a
ficocianina

Key words:

remote sensing of water

cyanobacteria

chlorophyll a

phycocyanin

\begin{abstract}
R E S U M O
Florações de fitoplanctôn podem constituir em riscos à saúde humana e biota aquática, sendo necessários o monitoramento da comunidade fitoplanctônica e a adoção de mecanismos visando à prevenção de sua ocorrência. Neste contexto métodos tradicionais de monitoramento podem ser mais efetivos se complementados por abordagens que utilizam as propriedades ópticas dos pigmentos fitoplanctônicos por meio do Sensoriamento Remoto. Com o objetivo de avaliar o potencial de dados espectrais multifonte na detecção remota do fitoplâncton, foi selecionada uma área de estudo no reservatório de Nova Avanhandava, SP, caracterizada por intensa atividade agrícola no seu entorno. Para esta análise foram adquiridos dados hiperespectrais em campo e imagens multiespectrais Modis e RapidEye, os quais foram relacionados a variáveis limnológicas indicadoras do comportamento fitoplanctônico; clorofila a e ficocianina. Os resultados mostram que imagens multiespectrais permitem uma avaliação da biomassa fitoplanctônica pela clorofila a; contudo, para ficocianina, pigmento fitoplanctônico diagnóstico da presença de cianobactérias, dados mais refinados são necessários, tais como os hiperespectrais.
\end{abstract}

\section{Multisource remote sensing applied to the detection of phytoplankton in inland waters}

\begin{abstract}
A B S T R A C T
Blooms of phytoplankton can be a risk to human health and aquatic biota, so the adoption of monitoring methods of phytoplankton and mechanisms for preventing its occurrence are needed. Thus, traditional monitoring methods could be more effective if complemented by approaches using the optical properties of phytoplankton pigments by means of Remote Sensing. In order to evaluate the potential of multi-scale remote sensing for detection of the phytoplankton activity, a study area was selected in Nova Avanhandava reservoir, located in the Tietê River, SP. For this analysis, hyperspectral field data and multispectral images of low and medium spatial resolution (Modis and RapidEye) were acquired and were related to indicator limnological variables of phytoplankton behavior; chlorophyll a and phycocyanin. The results show that a specific spectral band of RapidEye system $(690-730 \mathrm{~nm})$ allowed detect chlorophyll a and to evaluate the phytoplankton biomass, however hyperspectral data are needed to detect the phycocyanin pigment, indicative of cyanobacteria.
\end{abstract}




\section{INTRODUÇÃO}

A redução da qualidade das águas dos rios, reservatórios, estuários e regiões costeiras, é uma preocupação mundial visto que resulta na restrição de seus múltiplos usos e contribui para o aumento da ocorrência de doenças de veiculação hídrica provocadas pelo contato primário ou pela ingestão de água contaminada. As principais causas de alteração nas condições naturais dos ambientes estão relacionadas ao aporte de nutrientes e poluentes de origem difusa e/ou pontual, comumente originários de ações antrópicas. Um indicador imediato da eutrofização é a proliferação de fitoplâncton e macrófitas aquáticas no ambiente (Calijuri et al., 2006). Segundo Esteves (1998), as atividades agrícolas podem ter grandes efeitos na eutrofização artificial dos corpos d'água, associadas principalmente a perdas de nutrientes a partir das terras cultivadas, seja pela lavagem superior do solo após as primeiras chuvas ou por lavagem e percolação de nutrientes solúveis que atingem o lençol freático. Outro fator de impacto sobre o ambiente aquático é favorecido pelos pesticidas e agrotóxicos, conforme relatado por Dellamatrice \& Monteiro (2014).

A proliferação massiva de fitoplâncton já foi registrada em diversos países como Austrália, Inglaterra, China, África do Sul, inclusive no Brasil. Algumas tipologias, como as cianobactérias, são capazes de produzir e liberar, do meio, toxinas altamente prejudiciais à saúde humana e ao ecossistema aquático (Anderson et al., 2002; Eliott, 2012; Carey et al., 2012).

Atualmente, o monitoramento das comunidades fitoplanctônicas é realizado com a identificação de espécies e o acompanhamento de sua densidade, por meio de contagem de indivíduos. Tais métodos nem sempre são eficientes pelo fato da resolução temporal e espacial da amostragem convencional não permitir avaliar mudanças na biomassa do fitoplâncton, dificultando a adoção de mecanismos para a prevenção de sua ocorrência de modo que, em muitos casos, ações de controle são tomadas depois que o ambiente se encontra totalmente infestado (Calijuri et al., 2006).

Neste sentido, pesquisadores e gestores analisam diversas substânciase seres vivos presentes na água, tentando relacionar sua presença a padrões de qualidade (Ferreira \& Galo, 2012). Nesta categoria se inserem os pigmentos fitoplanctônicos que têm a propriedade de ser opticamente ativos viabilizando a utilização de sensores de radiação na sua deteç̧ão. Desta forma, o Sensoriamento Remoto torna-se uma alternativa eficaz no monitoramento da qualidade da água por meio da análise e quantificação de pigmentos específicos do fitoplâncton, tais como as clorofilas, carotenoides e ficobilinas (Kirk, 1994).

As propriedades ópticas dos componentes da água são examinadas em diversas abordagens do Sensoriamento Remoto: na obtenção da distribuição temporal e espacial do fitoplâncton; no monitoramento de extensas áreas visando ao diagnóstico preventivo de sua proliferação e por fornecer uma visão sinóptica da heterogeneidade na sua distribuição espacial, entre outras. O pigmento fitoplanctônico clorofila a é o componente opticamente ativo mais estudado de vez que está presente em todos os organismos fitoplanctônicos permitindo estimar o total de biomassa (Vincent et al., 2004). No caso das cianobactérias sua discriminação é possível por meio do pigmento ficocianina que possui propriedades ópticas peculiares, inclusive fluorescentes (Matthews et al., 2010; Agha et al., 2012; Mishra et al., 2013; Song et al., 2013).

Neste contexto, com o objetivo de avaliar o potencial de dados espectrais multifonte na detecção remota do fitoplâncton, foi selecionada uma área de estudo localizada no médio rio Tiête, especificamente no reservatório de Nova Avanhandava, SP. Neste reservatório, como nos demais ao longo da cascata do rio Tietê, o aumento populacional, a intensificação da atividade agrícola e a diversificação de usos têm incrementado consideravelmente o processo de degradação da qualidade da água.

\section{Material e Métodos}

A área de estudo localiza-se no médio curso do Rio Tiête, no município de Buritama-SP. A área de cobertura do reservatório é de $210 \mathrm{~km}$, vazão média anual de $688 \mathrm{~m}^{3} \mathrm{~s}^{-1}$ e profundidade média de $13 \mathrm{~m}$. O tempo de residência da água varia de 32 a 119 dias e recebe a contribuição de quatro tributários principais: rio dos Patos, ribeirão dos Ferreiros, ribeirão Bonito e ribeirão Lageado (AES Tietê, 2011). A bacia apresenta disposição de detritos urbanos e carga orgânica industrial porém é a intensa atividade agrícola, sobretudo o cultivo da cana-de-açúcar predominante na região, que causa os maiores impactos sobre o ambiente aquático.

Uma seção transversal do reservatório de aproximadamente $4,5 \mathrm{~km}$, totalizando $8,4 \mathrm{~km}^{2}$ de área, foi selecionada com área de estudo visto que em estudos anteriores indicou variabilidade na densidade de fitoplanctôn. A Figura 1A apresenta a localização do Reservatório de Nova Avanhandava no estado de São Paulo com a demarcação da subárea em vermelho. A composição colorida de imagem RapidEye (bandas espectrais 3, 2 e 1, associadas às cores vermelha, verde e azul, respectivamente) permite visualizar a cobertura do solo essencialmente agrícola no entorno do reservatório, caracterizada por áreas de cultivo

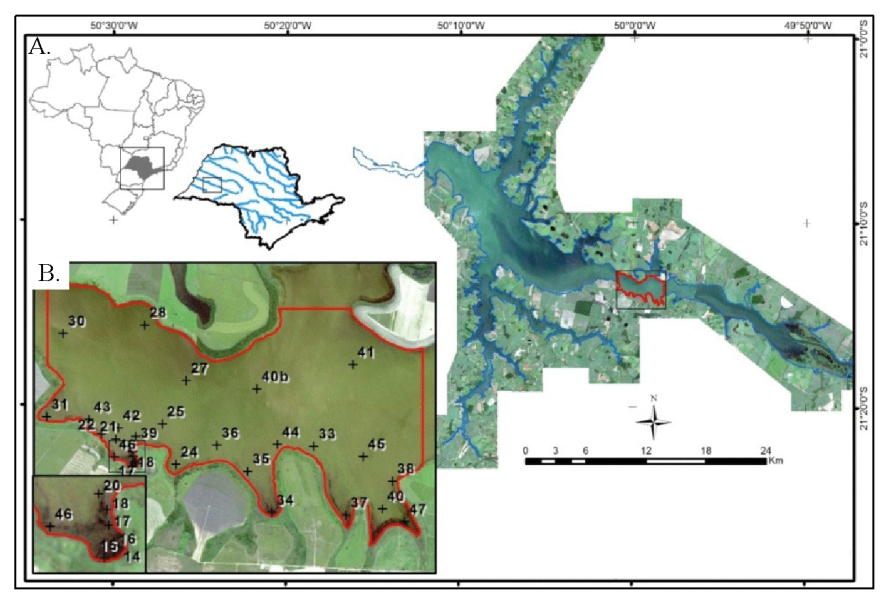

Figura 1. Composição colorida RapidEye (R3G2B1) com delimitação da área de estudo no reservatório de Nova Avanhandava (polígono em vermelho) (A) e distribuição dos elementos amostrais utilizados para coleta de dados em campo (B) 
em tons esverdeados e homogêneos, associados ao padrão característico de demarcação de talhões e plantio em nível.

$\mathrm{Na}$ área de estudo selecionada foi realizado um levantamento de campo nos dias 15 e 16 de fevereiro de 2012, de acordo com delineamento amostral especificado anteriormente. Nos elementos amostrais indicados na Figura 1B foram realizadas medidas fluorimétricas georreferenciadas das variáveis limnológicas biológicas clorofila a e ficocianina e adquiridas as curvas de reflectância espectral com um espectrorradiômetro de campo. Para a identificação de espécies fitoplanctônicas em amostra de água foi utilizado o método de contagem Utermõhl por número de indivíduos (Uhelinger, 1964).

O levantamento de campo foi realizado entre 10 e $15 \mathrm{~h}$, período de maior disponibilidade de radiação solar para aquisição dos dados espectrorradiométricos. A época do ano (verão) foi definida por ser a mais propícia para a proliferação do fitoplâncton, em virtude de altas temperaturas, aumento da descarga de nutrientes pelas chuvas e baixa velocidade dos ventos (Esteves, 1998). As imagens foram adquiridas em datas mais próximas possível do levantamento de campo a fim de se manter as mesmas condições ambientais (Matthews et al., 2010).

A imagem Modis (Moderate Resolution Imaging Spectroradiometer) utilizada refere-se ao produto MOD09A1, com resolução espacial de 500 m (Liang, 2002), adquirida da plataforma orbital Terra. Este produto é uma composição de imagens obtidas em um intervalo de 9 dias mas com data de tomada registrada em 10 de fevereiro de 2012; neste estudo foram usadas as bandas $3(459-479 \mathrm{~nm}), 4(545-565 \mathrm{~nm})$ e $1(620-670 \mathrm{~nm})$ as quais, de acordo Kirk (1994) e Gitelson (1992), estão definidas nas regiões espectrais mais propícias para detecção do fitoplâncton. Os produtos MOD09 fornecem valores de reflectância de superfície sem a necessidade de correção atmosférica.

A imagem RapidEye foi adquirida em 16 de fevereiro de 2012, com nível 3A de pré-processamento no qual a imagem é submetida a processo de ortorretificação, com suavização por convolução cúbica. A imagem resultante tem resolução espacial de $5 \mathrm{~m}$ e resolução radiométrica de 12 bits. As bandas espectrais do sensor são: Azul (440 - 510 nm), Verde (520-590 nm), Vermelho (630-685 nm), Vermelho Limítrofe (690-730 nm) e Infravermelho Próximo (760-850 nm). A Figura 2 apresenta um fluxograma das atividades realizadas na pesquisa enfatizando a abordagem multiescala adotada.

Conforme mostra essa figura, a partir da seleção da área de estudo foi definido um esquema de amostragem para a aquisição de dados em campo prevendo a inserção de um número maior de pontos de coleta nas áreas de maior resposta espectral nas bandas da região do verde (500$590 \mathrm{~nm})$ e vermelho limítrofe $(690-730 \mathrm{~nm})$ da imagem RapidEye. Tal procedimento partiu da identificação prévia de águas espectralmente distintas, selecionadas em uma imagem sintética Rapideye da mesma época da realização do trabalho de campo, porém do ano anterior. A imagem sintética foi gerada pela razão entre as bandas do vermelho limítrofe e verde, correspondentes à região espectral mais susceptível à variação da reflectância em função do fitoplâncton (Kirk, 1994).

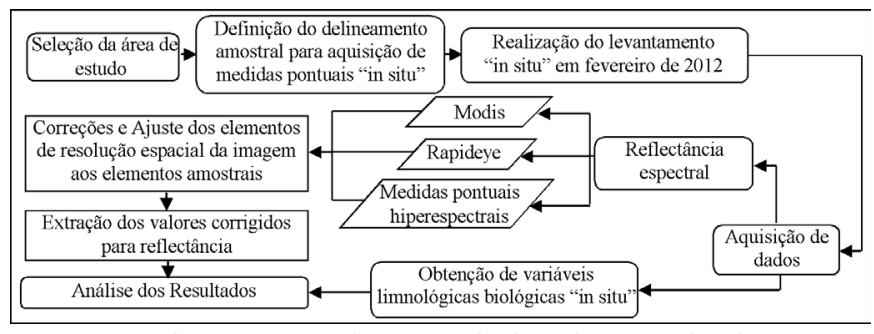

Figura 2. Fluxograma das atividades desenvolvidas

Para garantir uma melhor representatividade em áreas com maior variabilidade, foram identificadas as regiões do reservatório com maior desvio padrão na imagem sintética gerada pela razão. No total, foram distribuídos 30 elementos amostrais considerando-se o tempo e a logística do levantamento de campo. A Figura 1B mostra a distribuição dos pontos de coleta georreferencidos na área de estudo.

As imagens RapidEye passaram por pré-processamentos para obtenção de valores de reflectância de superfície utilizando-se o aplicativo FLAASH (Fast Line-of-sight Atmospheric Analysis of Spectral Hypercubes), do software ENVI 4.4. A correção radiométrica implementada no FLAASH se baseia no código MODTRAN4, cujo modelo procura minimizar os efeitos de espalhamento e absorção dos gases da atmosfera; posteriormente foram extraídos os valores de reflectância dos pixels da imagem correspondentes aos pontos georreferenciados definidos no delineamento amostral e medidos em campo.

Como a imagem Modis já vem convertida em valores de reflectância foi necessário ajustar a posição dos elementos amostrais obtidos em campo com os pixels da imagem, em virtude da diferença de escala, caso em que os 30 pontos georreferenciados coletados em campo se restringiram a 11 pixels espacialmente correspondentes na imagem Modis (devido ao tamanho do elemento de resolução da imagem no terreno, que é de $500 \mathrm{~m}$ ). Pontos localizados próximos à margem foram naturalmente excluídos pela ocorrência de mistura espectral com a vegetação presente no entorno do reservatório.

A concentração dos pigmentos fitoplanctônicos foi obtida por fluorimetria "in vivo", utilizando-se o fluorômetro 10AU da Turner Designs, para detecção por fluorescência da clorofila a e um fluorômetro Unilux, da Chelsea Technologies, usado para detectar e quantificar o pigmento ficocianina. A identificação dos grupos fitoplanctônicos foi realizada para distinguir os gêneros e espécies presentes na amostra $\mathrm{e}$ verificar se havia dominância do grupo de cianobactérias.

Os dados hiperespectrais do reservatório foram expressos na forma de curvas espectrais coletadas com o espectrorradiômetro FieldSpec HandHeld, modelo UV/VNIR (325-1075 nm). A variável medida foi o fator de reflectância hemisférico cônico (FRHC), que considera medidas com maiores ângulos de IFOV e iluminação ambiente e campo de visada instrumental constante (Schaepman-Strub et al., 2006). Essas curvas de reflectância, juntamente com os valores espectrais extraídos das imagens Rapideye e Modis, foram submetidas a uma análise de correlacão com os valores de clorofila a e ficocianina, obtidos por fluorimetria, a fim de avaliar o potencial das imagens multiespectrais RapidEye e Modis na detecção remota do fitoplâncton. 
Para a identificação de coeficientes de correlação significativos que indicassem dependência entre dados e variáveis limnológicas e considerando o número de elementos amostrais e o grau de significância, foi utilizado o teste de significância de Fisher; para os 30 elementos coletados em campo a nível de significância de $1 \%$ e limiar de aceitação de 99\%, o valor de correlação considerado aceitável foi acima de 0,42 . Com a redução no tamanho da amostra para 11 elementos, quando da análise da imagem Modis, o valor de correlação expressivo passou a ser de 0,68.

\section{Resultados e Discussão}

No primeiro dia do levantamento de campo foi observado florescimento de algas; contudo, como o céu se apresentava nublado, não foi possível a obtenção das curvas de reflectância espectral, de modo que as medidas radiométricas foram feitas no dia 16 de fevereiro. Porém na noite do dia anterior o reservatório passou por um longo período de precipitação, aproximadamente 2,8 $\mathrm{mm}$ (conforme registrado pela estação meteorológica local), o que auxiliou na dissolução do fitoplâncton; no dia do levantamento o tempo estava instável com a presença de nuvens e chuvas esporádicas. A velocidade do vento foi baixa, com direção nordeste. A Tabela 1 apresenta os valores de concentração máximo e mínimo, a média, desvio padrão e coeficiente de variação obtidos a partir dos 30 elementos amostrais medidos em campo para as variáveis limnológicas biológicas clorofila a e ficocianina. Observa-se que a variável clorofila a ultrapassou, na média, o valor máximo aceitável previsto pela resolução CONAMA 357/2005 (Brasil, 2012), equivalente a $30 \mu g \mathrm{~L}^{-1}$, para água doce de Classe 2. Portanto, para esta época do ano o reservatório possui água inadequada para consumo humano mesmo após tratamento convencional, tal como para a recreação de contato primário (natação, esqui, mergulho), para a irrigação de plantas, para a aquicultura e para a atividade de pesca.

Adotou-se como referência para análise da ficocianina, o valor obtido por Brient et al. (2008), os quais mostraram que quando a concentração de ficocianina é maior que $10 \mu \mathrm{g} \mathrm{L}^{-1}$ as cianobactérias dominam o ambiente em densidades preocupantes. No total, cinco pontos ultrapassaram o valor de concentração proposto por Brient et al. (2008).

A Figura 3 mostra os grupos e gêneros de fitoplâncton identificados na área de estudo e sua densidade estimada (em Individuos $\mathrm{mL}^{-1}$ ) além da sua proporção de ocorrência.

De acordo com a Figura 3, o grupo das cianobactérias (Cyanophyceae) domina o ambiente com proporção equivalente a $60 \%$. Dentre os principais gêneros presentes pode-se citar, como dominantes, o Microcystis e Rhodomona, capazes de liberar toxinas no ambiente.

Os dados hiperespectrais foram coletados nos 30 elementos amostrais com o intuito de observar as feições espectrais diagnósticos da presença dos pigmentos clorofila

\begin{tabular}{ccc} 
Grupo & Gênero & Ind $\mathrm{ml}-1$ \\
\hline \multirow{2}{*}{ Bacillariophyceae } & Aulacoseira sp1 & 26 \\
& Caloneis sp & 34 \\
& Trachelomonas sp1 & 163 \\
\hline \multirow{2}{*}{ Chlorophyceae } & Asterococcus cflimneticus & 34 \\
& Eutetramorus sp1 & 9 \\
\hline Cryptophyceae & Rhodomonas cf minuta & 566 \\
\hline & Microsystis sp & 1090 \\
Cyanophyceae & Microsystis sp2 & 94 \\
& Microsystis sp3 & 51 \\
& Pseudanabaena sp1 & 86 \\
\hline Euglenophyceae & Mallomonas sp2 & 17 \\
\hline \multirow{2}{*}{ Zygnemaphyceae } & Gonatozygon pilosum & 26 \\
& Sirogonium sp & 9
\end{tabular}

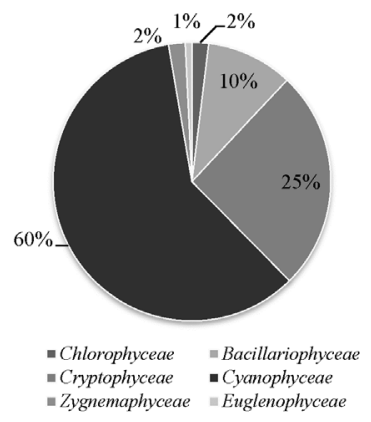

Figura 3. Gêneros e espécies fitoplanctônicas identificados em alíquota de água coletada na área de estudo

a e ficocianina. O tratamento das curvas de reflectância iniciou-se com a aplicação de um filtro de média móvel de cinco pontos para reduzir o comportamento aleatório decorrentes da presença de ruídos. As curvas espectrais resultantes são apresentadas na Figura 4, na qual as setas representam as feições características da presença de pigmentos fotossintetizantes, conforme descrito em Kirk (1994) e Gitelson (1992).

Relacionando o comportamento espectral com a presença de pigmentos fotossintetizantes verifica-se que nos menores comprimentos de onda (principalmente entre 400 a $500 \mathrm{~nm}$ ) ocorre ampla feição de absorção ocasionada pela clorofila a (Kirk, 1994). As curvas espectrais mostram uma região de reflectância máxima no verde entre 550 a $570 \mathrm{~nm}$, uma feição de absorção no vermelho em $675 \mathrm{~nm}$ e pico de reflectância no infravermelho próximo $(700 \mathrm{~nm})$, também ocasionada pela presença da clorofila a. O pico pouco representativo em $750 \mathrm{~nm}$ pode ser atribuído à somatória do espalhamento por células do fitoplâncton e por TSS (Kirk, 1994). Todas essas características espectrais também foram observadas

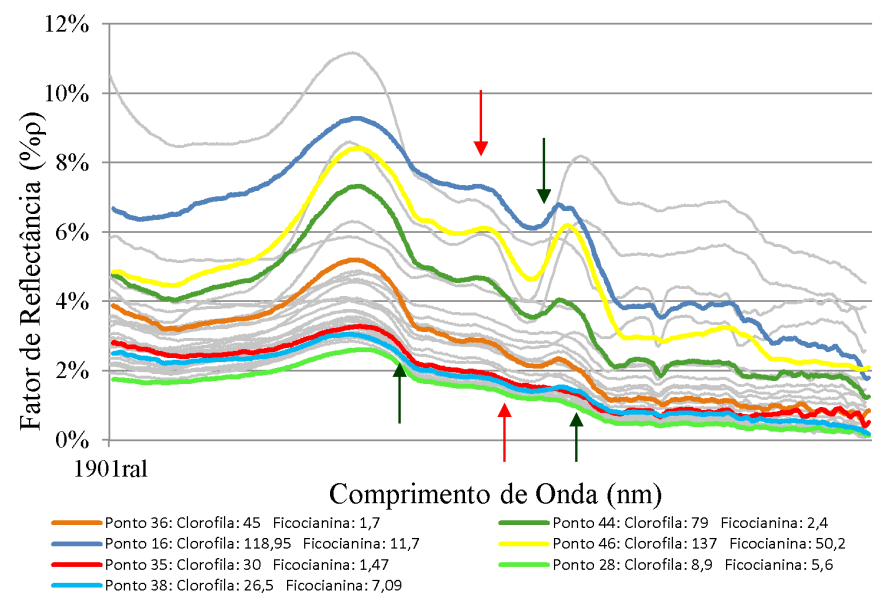

Figura 4. Curvas de reflectância espectral suavizadas dos 30 pontos amostrados. As curvas espectrais em destaque representam a variação espectral relacionada com a concentração de ficocianina (setas vermelhas) e clorofila a (setas verdes) em $\mu \mathrm{g} \mathrm{L}^{-1}$

Tabela1. Variáveis biológicas medidas no levantamento de campo

\begin{tabular}{cccccccc}
\hline Variáveis limonológicas biológicas & Máximo & Mínimo & Média & Desvio padrão & Coeficiente de variação (\%) & Referência $\mu \mathrm{g} \mathrm{L}^{-1}$ \\
Clorofila a $\left(\mu \mathrm{g} \mathrm{L}^{-1}\right)$ & 150,96 & 8,93 & 47,54 & 34,21 & 71 & $<3$ * $^{*}$ \\
Ficocianina $\left(\mu \mathrm{g} \mathrm{L}^{-1}\right)$ & 50,24 & 1,47 & 7,12 & 10,05 & 141 & $<10^{\star \star}$ \\
\hline
\end{tabular}

* Valores de referência segundo a resolução CONAMA 357/2005 para classe II (Brasil, 2012)

** Valores de referência segundo Brient et al. (2008) 
em curvas obtidas por Rundquist et al. (1996) e associadas à ocorrência de clorofila a. Ressalta-se, segundo Metsamaa et al. (2006), que as feições de espalhamento e absorção de clorofila a se tornam detectáveis nos espectros de reflectância quando a concentração de clorofila a é, em média, superior a $8 \mu \mathrm{g} \mathrm{L} \mathrm{L}^{-1}$.

Para o pigmento ficocianina, indicador da ocorrência de cianobactérias, foi possível visualizar em algumas curvas uma feição sutil de absorção próxima a $620 \mathrm{~nm}$ e um pico de espalhamento em torno de $650 \mathrm{~nm}$, conforme relatado na literatura para ambientes aquáticos com presença de cianobactérias (Matthews et al., 2010; Marion et al., 2012).

$\mathrm{Na}$ Figura 4 as curvas espectrais destacadas por cores apresentam, na legenda, as concentrações de clorofila a e ficocianina em $\mu \mathrm{g} \mathrm{L}^{-1}$, a fim de indicar a variação do comportamento espectral com oscilaçãoes na concentração desses pigmentos fitoplanctônicos. As setas verde (clorofila a) e vermelho (ficocianina) destacam os comportamentos de absorção e a reflexão nas curvas espectrais.

Os valores de reflectância extraídos das cinco bandas espectrais do RapidEye (B1 (440-510 nm), B2 (520-590 nm), B3 (630-685 nm), B4 (690-730 nm) e B5 (760-850 nm)), para os trinta pontos avaliados, são indicados na Figura 5A. As correlações entre os valores espectrais extraídos para os trinta pixels da imagem e as concentrações de ficocianina e clorofila a são mostradas graficamente na Figura 5B; para a análise de correlação também foram consideradas as razões B3/B2 e B3/ B4.

Observa-se, pela Figura 5A, certa heterogeneidade nos valores espectrais de alguns pixels, com alguns deles

A.

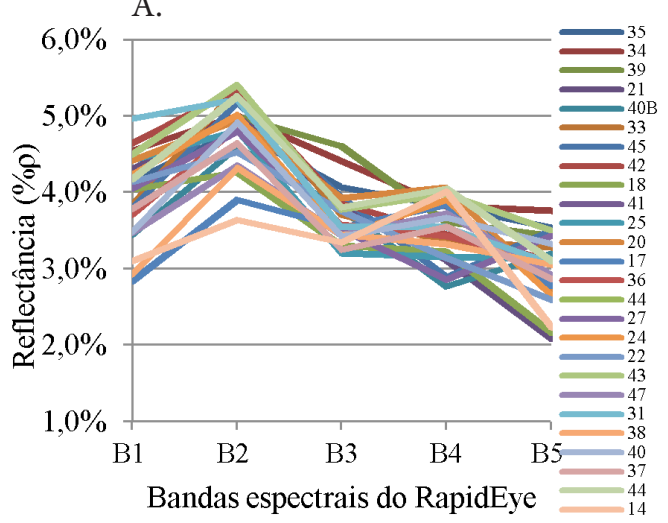

B.

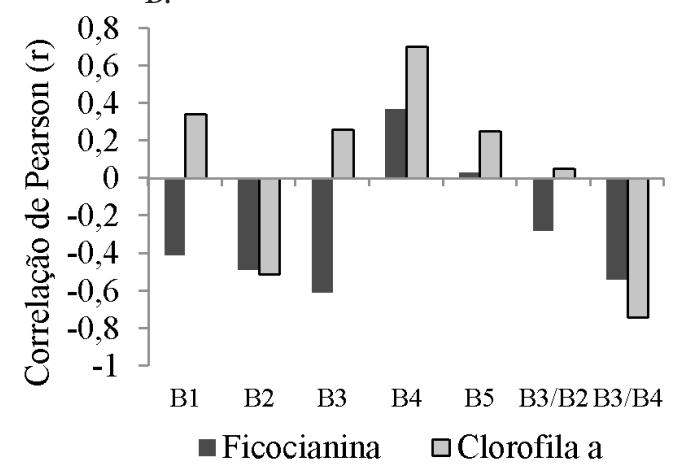

Figura 5. Valores de reflectância lidos nas bandas espectrais do RapidEye (A) e correlação entre valores de reflectância e de razões espectrais com concentração de clorofila a e ficocianina (B) atingindo até $5 \%$ de intensidade de reflectância. Na banda codificada como B3, centrada em $657,7 \mathrm{~nm}$, verifica-se que ocorre absorção na maioria das curvas. A banda centrada em $710 \mathrm{~nm}$ (B4) apresenta reflexão para a maioria das curvas; também é perceptível um comportamento de espalhamento na banda centrada em 555 nm (B2).

As correlações mostradas na Figura 5B foram significativas entre a Banda $4(690-730 \mu \mathrm{m})$ e a concentração de clorofila a, enquanto que a Banda 3 (B3: 630-685 $\mu \mathrm{m}$ ) apresentou maior correlação com o pigmento ficocianina. A razão entre as bandas B3 e B4 manteve correlação negativa moderada para ficocianina e correlação negativa alta para clorofila a. Pelos resultados verifica-se que a Banda 4 da imagem RapidEye foi mais apropriada para detectar a clorofila a. Com base nessas indicações foram testados modelos de regressão para explicitar a relação entre a concentração de clorofila a $\left(\mu \mathrm{g} \mathrm{L}^{-1}\right)$ e a banda $\mathrm{B} 4$ e razão B3/B4, cujos melhores resultados são apresentados na Figura 6, juntamente com os coeficientes de determinação $\left(\mathrm{R}^{2}\right)$. Os modelos de regressão para ficocianina definiram coeficientes de determinação pouco significativos não sendo possível estimar um modelo apropriado.

De acordo com os resultados apresentados na Figura 6, a utilização de modelos não lineares para relacionar a concentração de clorofila a com a razão das bandas B3 e B4 e os valores de reflectância da banda B3, apresentaram resultados significativos, lineares. Ferreira \& Galo (2012) encontraram resultados significativos em intervalos espectrais similares com utilização das bandas espectrais 3 (450-510 nm), 5 (630$690 \mathrm{~nm})$ e 6 (705 - $745 \mathrm{~nm})$ do sensor Wordview-2.

$\mathrm{Na}$ Figura 7A são apresentados os valores de reflectância espectral obtidos para as três bandas (B3 (459 - 479 nm),

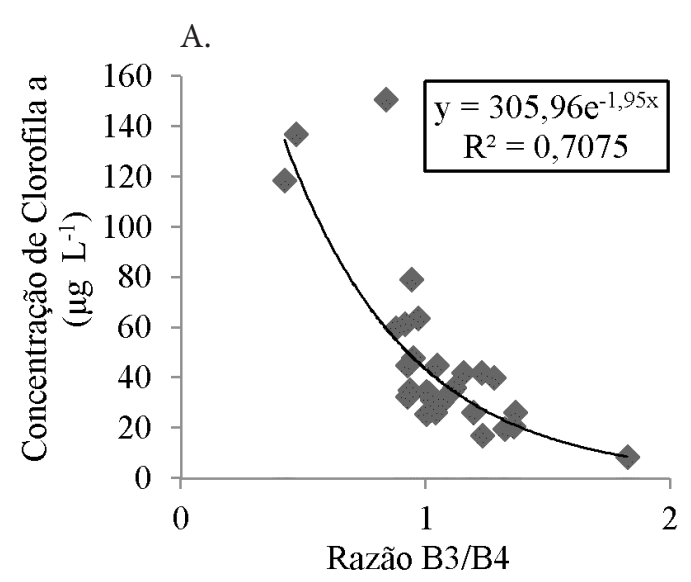

B.

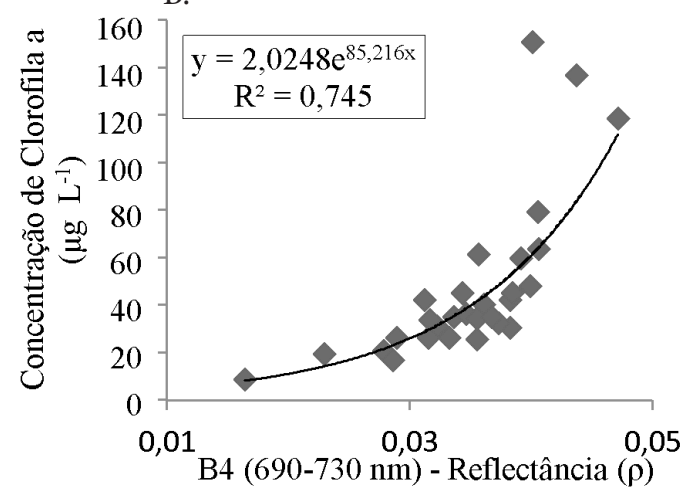

Figura 6. Modelos de regressão exponencial entre dados Rapideye e concentração de clorofila a 


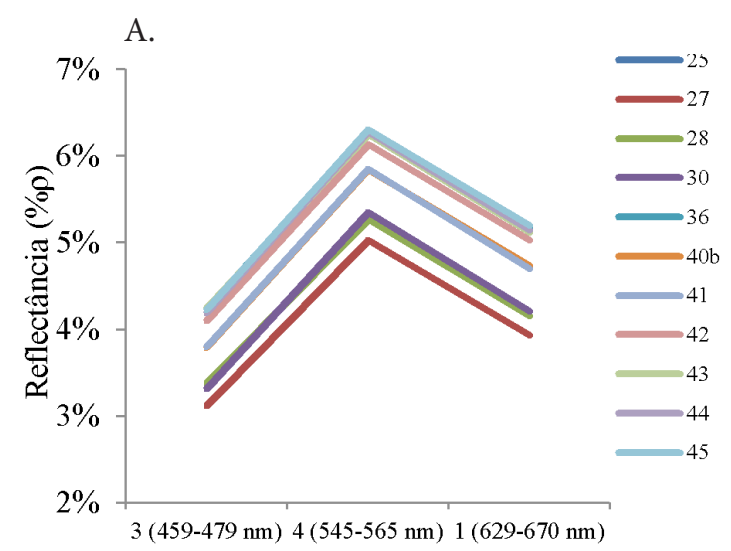

Bandas (Comprimento de onda)

B.

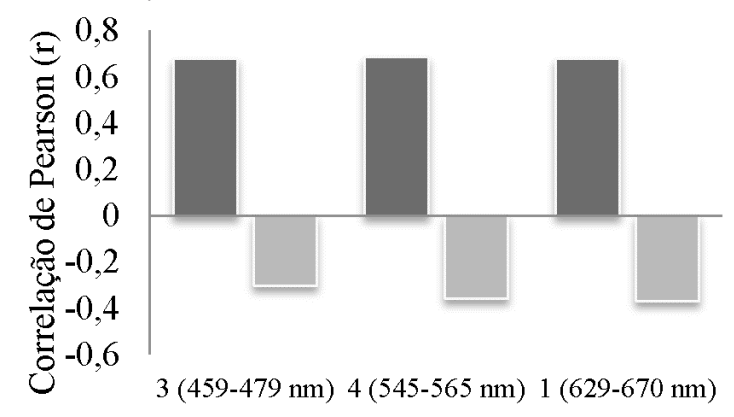

Bandas (Comprimento de onda - nm)

\section{- Clorofila a $\quad$ Ficocianina}

Figura 7. Valores de reflectância espectral do sensor Modis obtidos para os onze elementos amostrais considerados; (A) e correlação entre bandas extraídas do produto MOD09 e concentração de clorofila a e ficocianina (B)

B4 (545 - $565 \mathrm{~nm})$ e B1 (620 - $670 \mathrm{~nm}))$ do sensor Modis, nos intervalos espectrais mais apropriados para análise de pigmentos fitoplanctônicos.

Na Figura 7B estão indicadas as correlações entre essas bandas e as variáveis biológicas ficocianina e clorofila a, representativas da atividade fitoplanctônica no reservatório. Referida figura mostra que, mesmo com a baixa resolução espacial da imagem, foi possível observar alguma correlação (por volta de 0,68 ) com a clorofila a, embora considerando que as concentrações do pigmento foram medidas pontualmente e o valor extraído da imagem é a resposta espectral média registrada para a área do elemento de resolução no terreno (pixel). Para a ficocianina os valores de correlações obtidos foram pouco significativos.

As maiores correlações obtidas para o pigmento clorofila a (Figuras 5B e 7B) são consistentes com o que é descrito na literatura (Agha et al., 2012 e Matthews et al. 2010), que destaca a maior facilidade de detecção já que esta apresenta intensa resposta nas regiões de cobertura espectral dos sensores multiespectrais, diferentemente do pigmento ficocianina, que tem reposta espectral mais tênue.

Embora os valores de reflectância de algumas bandas das imagens Modis e RapidEye, indicassem correlações significativas com a concentração de clorofila a, a comparação direta entre essas imagens não é adequada para representar a capacidade de detecção do fitoplancton de cada uma, comparativamente, visto que não apenas suas resoluções espacias são incompatíveis mas também a definição espectral de suas bandas. Considerando que foram utilizadas medidas pontuais da concentração dos pigmentos fitoplanctônicos para relacionar com a resposta espectral de algumas bandas das imagens multiespectrais, fica evidente que a maior resolução espacial da imagem RapidEye permite uma representação mais fidedigna das condições observadas em campo já que a abrangência do pixel desta imagem é de $25 \mathrm{~m}^{2}$, enquanto que o pixel da imagem Modis se refere a uma área de 250.000 $\mathrm{m}^{2}$, gerando uma informação mais genérica e homogênea da resposta espectral dos 11 elementos amostrais.

\section{Conclusões}

1. Dados de Sensoriamento Remoto multiescala se mostraram úteis na detecção do fitoplâncton, mesmo nos casos da utilização das imagens multiespectrais de média resolução espacial.

2. As variáveis limnológicas obtidas (ficocianina e clorofila a) revelam que, no período analisado, o corpo d'água apresentou características de eutrofização com dominância do grupo de cianobactérias.

3. Para as imagens RapidEye, a Banda $4(690-730 \mathrm{~nm})$ foi mais propícia para detecção de clorofila a e a Banda 3 (630$685 \mathrm{~nm}$ ) para ficocianina; já para as cenas Modis todas as bandas apresentaram resultados significativos apenas para clorofila a.

\section{Literatura Citada}

AES Tiête Nova Avanhandava: AESTiête, 2011. Informações sobre o reservatório. <http://www.aestiete.com.br/usinas/Paginas/ NovaAvanhandava.asp>. 6 Nov. 2011.

Agha, R.; Cirés, S.; Wörmer, L.; Domínguez, J. A.; Quesada, A. Multi-sclae strategies for the monitoring of freshwater cyanobacteria: reducing the sources of uncertainty. Water Research, v.46, p.3043-3053, 2012. http://dx.doi.org/10.1016/j. watres.2012.03.005

Anderson, D.; Glibert, P. M.; Burkholder, J. M. Harmful algal blooms and eutrophication: nutrient sources, composition, and consequences. Estuaries, v.25, p.704-726, 2002. http://dx.doi. org/10.1007/BF02804901

Brasil. Resolução CONAMA n 357, de março de 2005. Conselho nacional do meio ambiente - CONAMA. Dispõe sobre a classificação dos corpos de água e diretrizes ambientais para o seu enquadramento. <http://www.mma.gov.br/port/conama/ res/res05/res35705.pdf>. 10 Jan. 2013.

Brient, L.; Lengronne, M.; Bertrand, E.; Rolland, D.; Sipel, A.; Steinmann, D.; Baudin, I.; Legeas, M.; Le, R. B.; Bormans, M. A phycocyanin probe as a tool for monitoring cyanobacteria in freshwater bodies. Journal of Environmental Monitoring, v.10, p.248-255, 2008. http://dx.doi.org/10.1039/b714238b

Calijuri, M. C.; Alves, M. S. A. A.; Santos, A. C. A. Cianobactérias e cianotoxinas em águas continentais. São Carlos: RiMa, 2006. 118p.

Carey, C. C.; Ibelings B. W.; Hoffmann, E. P.; Hamilton, D. P.; Brookes, J. D. Eco-physiological adaptations that favour freshwater cyanobacteria in a changing climate. Water Research, v.46, p.1394-1407, 2012. http://dx.doi.org/10.1016/j. watres.2011.12.016 
Dellamatrice, P. M.; Monteiro, R. T. R. Principais aspectos da poluição de rios brasileiros por pesticidas. Revista Brasileira de Engenharia Agrícola e Ambiental, v.18, n.12, p.1296-1301, 2014. http://dx.doi. org/10.1590/1807-1929/agriambi.v18n12p1296-1301

Eliott, J. A. Is the future blue-green? A review of the current model predictions of how climate change could affect pelagic freshwater cyanobacteria. Water Research, v.46, p.1364-1371, 2012. http:// dx.doi.org/10.1016/j.watres.2011.12.018

Esteves, F. A. Fundamentos de limnologia. Rio de Janeiro: FINEP. 2.ed., 1998. 575p.

Ferreira, M. S.; Galo, M. L. B. T. Chlorophyll a spational inference using artificial neural network from multispectral imagens and in situ measurements. Anais da Academia Brasileira de Ciências, v.85, p.519-532, 2013. http://dx.doi.org/10.1590/ S0001-37652013005000037

Gitelson, A. A. The peak near $700 \mathrm{~nm}$ on radiance spectra of algae and water: relationships of its magnitude and position with chlorophyll concentration. International Journal of Remote Sensing, v.13, p.3367-3373, 1992. http://dx.doi.org/10.1080/01431169208904125

Kirk, J. T. O. Light \& photosynthesis in aquatic ecosystems. v.2. London: Cambridge University Press, 1994. 507p. http://dx.doi. org/10.1017/CBO9780511623370

Liang, S. Validating MODIS land surface reflectance and albedo products: methods and preliminary results. Remote Sensing of Environment, v.83, p. 149-162, 2002. http://dx.doi.org/10.1016/ S0034-4257(02)00092-5

Marion, J. W.; Lee, J.; Wilkins, J. R.; Lemeshow, S.; Lee, C. Waletzko, E. J.; Buckley, T. J. In vivo phycocyanin flourometry as a potential rapid screening toolfor predicting elevated microcystin concentrations at eutrophic lakes. Environmental. Science \& Technology, v.46, p.4523-4531, 2012. http://dx.doi.org/10.1021/es203962u
Matthews, M. W.; Bernard, S.; Winter, K. Remote Sensing of cyanobacteria-dominant algal blooms and water quality parameters in Zeekonevlei, a small hypertrophic lake, using MERIS. Remote Sensing of Environment, v.114, p.2070-2087, 2010. http://dx.doi.org/10.1016/j.rse.2010.04.013

Metsamaa, L.; Kutser, T. Srömbeck, N. Recognising cyanobacterial blooms based on their optical signature: a modelling study. Boreal. Environment Research, v.11, p.493-506, 2006.

Mishra, S.; Lee, Z.; Tucker, C. S. Quantifying cyanobacterial phycocyanin concentration in turbid productive waters:A quasianalytical approach. Remote Sensing of Environment, v.133, p.141-151, 2013. http://dx.doi.org/10.1016/j.rse.2013.02.004

Rundquist, D. C.; Han, L.; Schalles, J. F.; Peake, J. S. Remote measurement of algal chlorophyll in surface waters: the case for the first derivative of reflectance near $690 \mathrm{~nm}$. Photogrammetric Engineering e Remote Sensing, v.62, p.195-200, 1996.

Schaepman-Strub, G. ; Schaepman, M. E. ; Painter, T. H.; Dangel, S.; Martonchik, J. V. Reflectance quantities in optical remote sensing - Definitions and case studies. Remote Sensing of Environment, v.103, p.27-42, 2006. http://dx.doi.org/10.1016/j.rse.2006.03.002

Song, K.; Li, L.; Tedesco ; L.; Clercin, N.; Hall, B.; Li, S.; Shi, K.; Liu, D.; Sun, Y. Remote estimation of phycocyanin (PC) for inland waters coupled with YSI PC fluorescence probe. Environmental Science and Pollution Research, p.1-11, 2013.

Uhelinger, V. Étude statistique des méthodes de dénobrement planctonique. Archives des Sciences, v.17, p.121-123, 1964.

Vincent, R. K.; Qin, X.; Mckay, R. M. L.; Miner, J. Czajkowski. Phycocyanin detection from LANDSAT TM data for mapping cyanobacterial blooms in Lake Erie. Remote Sensing of Environment, v.89, p.361-368, 2004. http://dx.doi.org/10.1016/j. rse.2003.10.014 